\title{
Adrenal Incidentaloma (Adrenaloma)
}

\author{
Dimitrios A. Linos
}

First Surgical Clinic Hygeia Hospital, Athens, Greece and Massachusetts General Hospital, Boston, MA USA

\section{ABSTRACT}

The management of adrenalomas should include the following:

1. A detailed history and physical examination to detect subtle evidence of hormonal hypersecretion or the possibility of metastatic carcinoma.

2. Hormonal studies:

- Short dexamethasone suppression test ( $2 \mathrm{mg}$ of dexamethasone) followed by a high-dose dexamethasone suppression test $(8 \mathrm{mg}), \mathrm{CRH}$ assay and analysis of the diurnal cortisol rhythm if serum cortisol value post dexamethasone is greater than $3 \mu \mathrm{g} / \mathrm{dL}$

- 24-hour (or spot) urinary catecholamine metabolites (metanephrine and normetanephrine)

- In the hypertensive or normotensive patient with serum potassium less than $3.9 \mathrm{nmol} / \mathrm{L}$, the upright aldosterone level to plasma renin activity (PRA) ratio.

3. Additional studies, such as

- Glucose tolerance test

- Bone mineral density evaluation

- Body composition and fat distribution by DEXA (Dual energy X-Ray absorptiometry).

The role of FNA is limited. It may be helpful only in the patient with coexistent extradrenal carcinoma to confirm adrenal metastasis. Although genetic and molecular biology studies do not have wide clinical application, they should be encouraged and supported.

Once all of these data are collected, the recommendations are:

1. All clearly nonfunctioning adrenalomas that are not suspicious for malignancy in asymptomatic patients should be observed for several years, mainly with hormonal studies, until their secretory and benign nature is confirmed.

2. All patients with adrenalomas and evidence of subclinical function, suspicion for malignancy (using size, imaging, FNA and molecular biology criteria) and symptoms, such as hypertension, obesity, impaired glucose tolerance, central fat deposition and reduced bone mineral density, should undergo laparoscopic adrenalectomy.

The age, the overall medical condition and the anxiety of the patient should also be considered in the decision to operate on a patient with an adrenaloma.

Key words: adrenal tumors, laparoscopic adrenalectomy, adrenal incidentaloma

Address correspondence and requests for reprints to:

Dimitrios A. Linos, M.D., F.A.C.S., Harvard Medical School, 227 Kifissias Avenue, Kifissia 145 61, Greece, Tel: 210-6125001,
Fax: 210-6126170, e-mail: dlinos@hms.harvard.edu Received 10-11-02, Revised 18-12-02, Accepted 27-12-02 


\section{INTRODUCTION}

The adrenal tumor that is discovered incidentally, usually during an imaging procedure (CT, MRI, ultrasound) for symptoms unrelated to adrenal disease (e.g, back pain) is called an incidentaloma.

These tumors seem nonfunctioning on the basis of clinical and essential laboratory findings. As more physicians (and patients on their own) order these easily available imaging studies for common diseases potentially related to adrenal pathology (and not the known syndromes), such as mild and non paroxysmal hypertension, diffuse obesity and diabetes, an increasing number of unsuspected (but hardly incidental) adrenal tumors are found. I have proposed that these tumors be included with the true incidentalomas under the broader term adrenaloma because they share the same diagnostic and therapeutic dilemmas. ${ }^{1}$

The term adrenaloma implies that the discovered tumor (incidentally or not) derives from the adrenal but is not obviously an aldosteronoma, a Cushing's syndrome adenoma, a pheochromocytoma, a virilizing or feminizing tumor or a functioning adrenal carcinoma. The widespread teaching is that most adrenalomas are indolent tumors, nonfunctioning and asymptomatic, causing no harm to the patient. ${ }^{2-5}$ Recent studies, however, have shown that a high percentage of these tumors can be subclinically functioning, causing symptoms milder than those encountered in the well known adrenal hyperfunctioning syndromes but still harmful to the patient. ${ }^{6-14}$ Thus, the screening tests of serum potassium, urinary VMA and serum cortisol do not suffice and more detailed and in depth laboratory investigation is necessary. The fear of adrenal carcinoma that dictated the approach to these tumors in the past (with the main emphasis on the size of the tumor) should be changed to the fear of the subtle function of these usually benign adrenal cortical adenomas with coexistent metabolic pathology (eg hypertension, obesity, diabetes).

\section{FREQUENCY}

The overall frequency of adrenal adenomas in 87,065 autopsies of 25 studies was $5.9 \%$ (range $1.1 \%$ to $32 \%) .{ }^{15}$ The frequency of adrenal masses discovered by CT, MRI or ultrasonography is somewhat lower. Abecassis et $\mathrm{al}^{16}$ in a 2-year period examined 1459 patients and found $63(4.3 \%)$ with adrenal masses. Of those, 19 patients (1.3\% of examined patients and $30 \%$ of patients with adrenal masses) had adrenalomas. At the Mayo Clinic, ${ }^{17}$ in a 5-year period 61,054 patients underwent CT scanning. In 2,066 (3.4\%) patients, an adrenal abnormality was found; among these, 259 patients $(12.5 \%)$ had an adrenaloma or adrenal lesion larger than $1 \mathrm{~cm}$, without biochemical evidence or symptoms suggestive of cortical or medullar hypersecretion or general constitutional symptoms suggestive of malignant disease. Similar findings have been described in more recent studies. ${ }^{18-20}$ Thus, in the era of widespread use of high-resolution ultrasonography, new generation CT scans and MRI, we can anticipate a $5 \%$ incidence of adrenalomas.

\section{PATHOLOGY}

The majority of surgically removed adrenalomas have been classified as nonfunctioning cortical adenomas. ${ }^{21-23}$ Benign masses such as nodular hyperplasia, adrenal cysts, myeololipomas, ganglioneuromas, hematomas, hamartomas, hemangiomas, leiomyomas, neurofibromas, teratomas, as well as infections (tuberculosis, fungal, echinococcosis, nocardiosis) are also included in the pathology of resected adrenalomas. Potentially lethal neoplasms, however, such as pheochromocytomas and primary carcinomas are always first on the list of resected adrenalomas. ${ }^{24-28}$ Pheochromocytoma is the most frequently found hormone-producing adrenaloma that occasionally has a normal preoperative laboratory evaluation. ${ }^{29-33}$ Few cases of aldosteronomas and androgen-producing adenomas have been described among cases of surgically removed adrenalomas. ${ }^{3-34}$ In a large multicenter, retrospective Italian study of 380 surgically treated adrenalomas (out of 1096 collected), 198 (52\%) were cortical adenomas, $47(12 \%)$ were cortical carcinomas, $42(11 \%)$ were pheochromocytomas and 93 were other less frequent tumors. ${ }^{7}$

\section{THE GOAL OF EVALUATION}

Although by definition the adrenalomas (incidentalomas) appear "nonfunctioning", on the basis of clinical and essential laboratory findings more and more investigators have shown that a high percentage of them may be subclinically functioning and/or associated with other metabolic abnormalities. In a multicenter, retrospective evaluation of 1096 patients with 
adrenal incidentaloma, the work-up revealed that 9.2\% had subclinical Cushing's syndrome, $4.2 \%$ had pheochromocytoma and $1.6 \%$ had clinically unsuspected aldosteronomas. ${ }^{22}$

Rossi et a $\mathrm{l}^{10}$ followed prospectively 50 consecutive patients with adrenaloma. Detailed hormonal investigation found 12 of $50(24 \%)$ to have subclinical Cushing's syndrome defined as abnormal response to at least 2 standard tests of the hypothalamus-pituitaryadrenal axis function, in the absence of clinical signs of Cushing's syndrome. In the same study, $92 \%$ of patients had hypertension, $50 \%$ obesity, $42 \%$ type 2 diabetes mellitus and $50 \%$ abnormal serum lipid concentration. The clinical and hormonal features improved in all patients treated by adrenalectomy but were unchanged in all those who did not undergo surgery (follow up 9-73 months).

Interestingly, all 13 patients who had resection of truly nonfunctioning adenomas because of large size had improved clinically to such an extent that antihypertensive and antidiabetic therapy was reduced or discontinued. All the improvements persisted during the follow-up.

Another multicenter study ${ }^{12}$ of 64 consecutive patients with adrenaloma found a higher than expected prevalence of abnormal glucose tolerance in $39(61 \%)$ patients. The same authors ${ }^{35}$ following 62 consecutive patients with adrenalomas found abnormal glucose tolerance in $66 \%$.

Midorikawa et al ${ }^{11}$ studying 15 patients with adrenaloma (4 with subclinical Cushing and 11 with truly nonfunctioning tumors) found a high prevalence of alteral glucose tolerance and insulin resistance. Adrenalectomy reversed insulin resistance in all patients with subclinical functioning and truly non functioning adrenal adenomas.

Terzolo et $\mathrm{al}^{8}$ followed 41 patients with adrenal incidentaloma (12 with subclinical Cushing's syndrome) and compared them with 41 controls. He found that the 2-h post-challenge glucose was significantly higher in patients than in controls. Similarly, both systolic and diastolic blood pressures were higher in patients. The calculated whole-body insulin sensitivity index (derived from the oral glucose tolerance test) was significantly reduced in the patients. They concluded that patients with adrenal adenoma (subclinically functioning or nonfunctioning) display some features of the metabolic syndrome such as impaired glucose tolerance, increased blood pressure and high triglyceride levels.

Garrapa et $\mathrm{al}^{3}$ evaluated body composition and fat distribution, as measured by DEXA (Dual-energy XRay absorptiometry) in women with non functioning adrenalomas and in women with Cushing's syndrome compared with healthy controls matched for age, menopausal status and BMI. Women with adrenalomas had larger waist circumference reflecting intraabdominal fat. The BP was higher in patients with adrenaloma than controls and $50 \%$ of patients with adrenaloma were hypertensive. HDL cholesterol levels and triglyceride mean values were also higher in patients with adrenaloma than in controls. If central fat deposition, hypertension and low HDL are important risk factors for cardiovascular disease then patients with adrenaloma, whether subclinically functioning or nonfunctioning are at higher risk than the general population for cardiovascular disease.

Chiodin et $\mathrm{l}^{14}$ performed a longitudinal study evaluating the rate of spinal and femoral bone loss levels in 24 women with adrenaloma. They were divided into two groups on the basis of the median value of urinary cortisol excretion. The group with higher cortisol values (subclinical Cushing levels) had more lumbar trabecular bone loss than those with low cortisol secretion (not hypersecreting tumors).

Therefore the cavalier attitude towards adrenalomas should be changed. These tumors are at an intermediate stage in between normal and pathological. They should be screened to rule out a) Subclinical Cushing's syndrome b) Subclinical pheochromocytoma c) Subclinical primary aldosteronism d) Adrenal carcinoma (primary or solitary metastasis)

\section{SCREENING FOR SUBCLINICAL CUSHING'S SYNDROME}

Patients with subclinical Cushing's syndrome have none of the signs and symptoms of the typical Cushing's syndrome (plethora, moon face, central obesity, easy bruising, proximate muscle weakness, acne, osteoporosis etc.)

The frequency of subclinical Cushing's syndrome among patients with adrenaloma ranges from 12$24 \% .^{36,10}$ 
Depending on the amount of glucocorticoids secreted, the clinical significance of subclinical Cushing's syndrome ranges from slightly attenuated diurnal cortisol rhythm to atrophy of the contralateral adrenal gland, a dangerous condition after unilateral adrenalectomy, if appropriate therapeutic measures are not taken early enough. ${ }^{37}$

The best screening test for autonomous cortisol secretion is the short dexamethasone suppression test. A 2-mg or 3-mg dose is better than the usual 1-mg dose to reduce false-positive results. A suppressed serum cortisol ( $<3 \mu \mathrm{g} / \mathrm{dL}$ or $80 \mathrm{nmol} / \mathrm{L}$ ) excludes Cushing's syndrome. A serum cortisol greater than $3 \mu \mathrm{g} / \mathrm{dL}$ requires further investigation, including a confirmatory high-dose dexamethasone suppression test $(8 \mathrm{mg})$, corticotropin-releasing hormone ( $\mathrm{CRH})$ test and analysis of diurnal cortisol rhythm. If serum cortisol concentrations are not suppressible by high-dose dexamethasone, the diagnosis of subclinical Cushing's syndrome is established. Another recently suggested test is the growth hormone $(\mathrm{GH})$ response to GHRH. A blunted GH release might prove a sensitive and early sign of subclinical Cushing's Syndrome ${ }^{8}$. As already discussed, glucose tolerance is altered in patients with adrenaloma (with and without subclinical Cushing) and a glucose tolerance test is recommended in patients with adrenaloma ${ }^{38,12}$. Finally, bone mineral density of the spine should be performed to detect reduced bone mass in patients with subclinical Cushing's syndrome. ${ }^{14}$

Adrenal scintigraphy with ${ }^{131}$ I-6 6 -iodomethylnorcholesterol (NP 59) can reveal a "functioning" but not "hypersecretory" tumor when there is an uptake of the nucleotide in the tumor site and no-uptake in the contralateral suppressed gland. Some authors ${ }^{39,40}$ suggested a significant positive correlation between abnormal cortical secretion and NP 59 uptake making NP 59 scanning a cost effective diagnostic tool for evaluating adrenalomas.

Others ${ }^{15}$ found it cumbersome because it requires several days to obtain the images and owing to the inability to take up NP 59 when there is hemorrhage or inflammation; they recommend no routine use of NP-59 scan.

\section{SCREENING FOR "SUBCLINICAL PHEOCHROMOCYTOMA"}

The typical patient with pheochromocytoma is hypertensive and may have paroxysmal hypertension and related symptoms (headache, hypertensive crisis, sweating and cardiac arrhythmias). The proposed term "subclinical pheochromocytoma" refers to the totally asymptomatic adrenaloma that histologically proves to be a pheochromocytoma. In several series of adrenalomas, the frequency of pheochromocytomas ranges from $10 \%$ to $40 \%{ }^{33,31}$ Although the percentage of asymptomatic pheochromocytomas among patients with nonfunctioning adrenal tumors is relatively high, most test positive on hormonal evaluation, which is a measurment of 24-hour urinary metanephrines and vanillylmandelic acid (VMA) or fractionated urinary catecholamines. In the National Italian Study Group, 27 patients (3.4\% of the total patients with incidentaloma) were found to have pheochromocytoma; 24-hour urinary catecholamine and VMA concentrations were elevated in $86 \%$ and $4.6 \%$ of patients, respectively, ${ }^{22}$ indicating that a combination of tests is more useful clinically than an individual test. The efficacy of single-voided ("spot") urine metanephrine and normetanephrine assays for diagnosing pheochromocytoma has recently been documented. Such tests may avoid the inconvenience of 24-hour urine collection. ${ }^{41}$

There is no indication for routine use of ${ }^{131}$ I-metaiodobenzylguanidine (I-MIBG) scintigraphy in the evaluation of an adrenaloma unless catecholamine and urinary metabolites are elevated.

Because there are cases of adrenalomas that preoperatively had negative urinary VMA, metanephrines and MIBG scanning but intraoperatively behaved (with later histologic proof) as pheochromocytomas, prophylactic measures should always be taken (e.g, arterial line, immediate access to intravenous nipride) during surgery.

\section{SCREENING FOR "SUBCLINICAL PRIMARY ALDOSTERONISM"}

The typical primary aldosteronism is characterized by hypertension with hypokalemia, elevation of plasma aldosterone and suppressed plasma renin activity. Subclinical primary aldosteronism describes the patient with adrenaloma who is normotensive or hyper- 
tensive with normokalemia. ${ }^{42}$ More than $40 \%$ of patients with primary aldosteronism are normokalemic; therefore, the previously recommended measurement of potassium as the only test to rule out primary aldosteronism in the case of adrenaloma should be abandoned. ${ }^{45}$ Instead, a detailed time-consuming evaluation is necessary, especially in all hypertensive patients, to rule out primary aldosteronism which may be the cause of hypertension in up to $15 \%$ of these patients. $^{43,44}$ In a normotensive patient with a serum potassium level greater than $3.9 \mathrm{nmol} / \mathrm{L}$, no further hormonal evaluation is necessary. The screening for subclinical primary aldosteronism should include, in addition to serum potassium, the upright aldosterone level to plasma renin activity (PRA) ratio, since a single value of aldosterone may be normal. Patients with two or more samples with pathologic aldosterone/PRA ratio $(>40)$ should undergo the fluorocortisone suppression test ( $0.4 \mathrm{mg}$ every day for 4 days) or the acute saline suppression test ( $2 \mathrm{~L}$ of $0.9 \% \mathrm{NaCl}$ solution infused intravenously in 4 hours) to confirm the diagnosis. Bilateral adrenal venous sampling with measurements of aldosterone and cortisol levels is the necessary next step to lateralize, determine the subtype of primary aldosteronsim in order to identify the patient who will be cured through surgery.

\section{SCREENING FOR ADRENAL CARCINOMA}

The risk of an adrenaloma harboring a primary carcinoma of the adrenal is very low because the annual incidence of the latter has been estimated to range from 1 case per 600,000 to 1 case per 1.6 million persons. Its prevalence is approximately $0.0012 \% .{ }^{46} \mathrm{In}$ contrast, metastatic carcinoma to the adrenal is a common finding in patients with lung, breast, colon and other extra-adrenal malignancies. In published series of surgically resected adrenalomas, the frequency of histologically confirmed primary adrenal carcinoma ranges from $4.2 \%$ to $25 \% .^{7}$ The frequency of adrenal metastasis from lung cancer at autopsy ranges from $17 \%$ to $38 \%$. In patients with adrenal mass in the setting of extra-adrenal malignancy, the probability of this mass being metastatic ranges from $32 \%$ to $73 \% .^{33,5,47}$

\section{Size of tumor}

The size of an adrenaloma is frequently used to predict potential malignancy and the need for surgery. Although most clinically treated adrenal malignancies are discovered when they are larger than $6 \mathrm{~cm}$ in diameter, several reports have described very large tumors that never metastasized and small adrenal tumors that did (Figure 1). In several series, adrenocortical carcinomas with a maximum diameter of $3 \mathrm{~cm}$ or less have been described. . $^{37,47,33,15}$

The size of an adrenaloma as reported on a CT scan is usually less than the size reported on the histology report. This underestimation ranges from $16 \%$
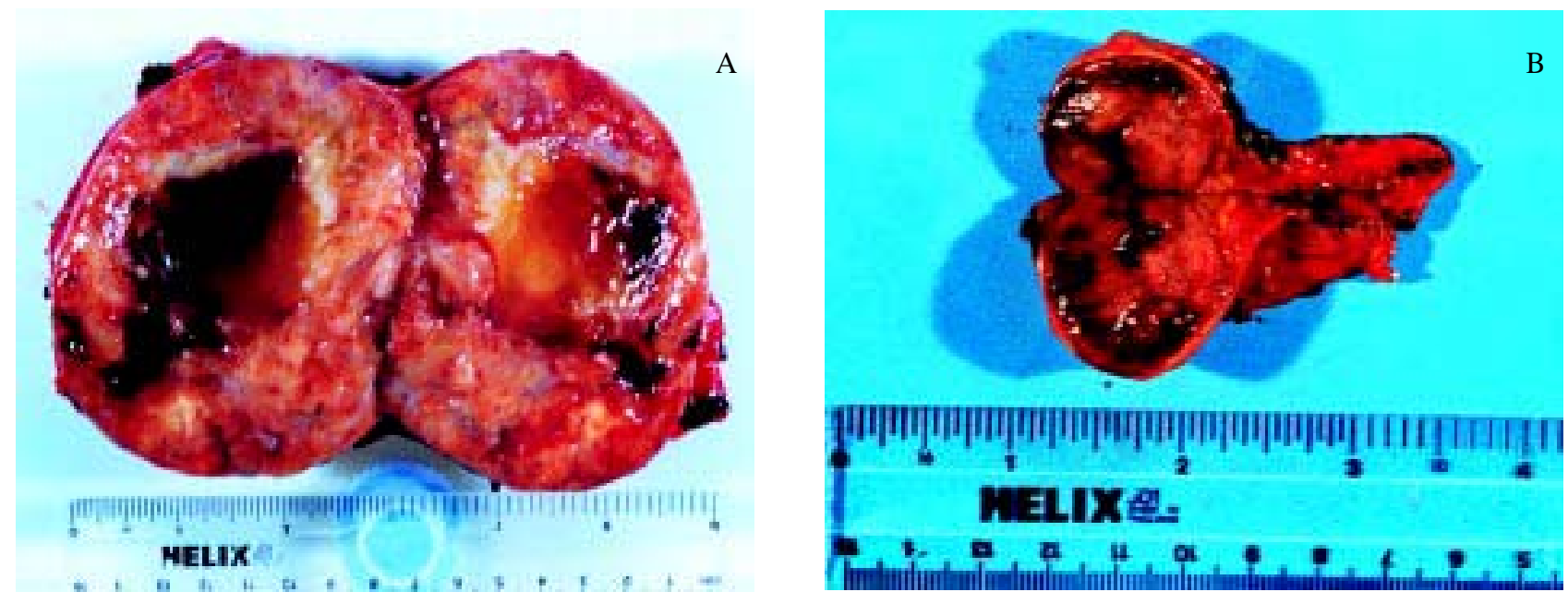

Figure 1. The size should not be the main indicator for surgery: A) this 9x8x8cm adrenal incidentaloma found on a 55 y.o. male proved to be a benign swanoma, B) this $2.8 \times 2.8 \times 2.3 \mathrm{~cm}$ adrenal incidentaloma found on a 43 y.o. male proved to be a pheochromocytoma, a potentially lethal tumor. 
to $47 \% .^{48}$ In an analysis of the CT and histology reports of 76 patients with various diseases, we found that the mean estimated diameter of the adrenal tumor was $4.64 \mathrm{~cm}$ on the CT report when the real size (pathology report) was $5.96 \mathrm{~cm}$. Further analysis of different CT scans revealed a consistent underestimation in all groups. In the group of adrenal tumors with a maximum diameter of less than $3 \mathrm{~cm}$, the mean diameter reported on CT was $2.32 \mathrm{~cm}$ in contrast to the true histological size of $3.63 \mathrm{~cm}(\mathrm{P}<0.001)$. We therefore proposed the formula Histologic Size $=0.85+$ (1.09 X CT size) to correct the underestimated CT size so as to use the size criterion more accurately. ${ }^{48}$

\section{Imaging}

In addition to assessing distant metastasis and tumor size, imaging studies may suggest malignancy. On a CT study, one may see a poorly delineated rugged tumor with stippled calcifications and with areas of necrosis; such lesions are suggestive of malignancy, especially if enlarged lymph nodes or local invasion is also detected. ${ }^{49}$

On MR imaging studies, one should look for heterogeneously increased, early T2-weighted signal, weak and late enhancement after gadolinium injection or an intravascular signal identical to the tumor signal. When NP59 scintigraphy is available, the lack of (or very weak) uptake in the tumor and normal contralateral uptake is suspicious for malignancy. Positron emission tomography (PET) can be used following the administration of 2-deoxy-2[ $\left.{ }^{18 F}\right]$ fluoro-D-glucose. The 18 F-FDG-PET-scan is a useful tool confirming isolated metastases and selecting patients for adrenalectomy. It has been used in studies to distinguish between primary and metastatic adrenal lesions, especially in patients with other primary malignan$\operatorname{cies}^{50}$ (Figure 2).

\section{Fine-Needle Aspiration}

Fine-needle aspiration (FNA) biopsy of an adrenaloma has a limited role. It is useful in cases of coexistent extra-adrenal carcinoma (usually lung cancer) to confirm the radiologic evidence of adrenal metastasis. The sensitivity of preoperative FNA in a series of 23 patients who had a laparoscopic approach for adrenal carcinoma was only 57\% (4 of 6 true positives for adrenal metastasis and 0 of 1 true positive for primary adrenal cancer) ${ }^{50 a}$ Generally, FNA cannot differentiate cortical adenoma form carcinoma because it cannot detect invasion of the tumor into the capsule.

In a study by Silverman and co-workers ${ }^{51}, 3$ of 33 FNA specimens that contained "benign" adrenal tissue were later proved to be malignant. Each malignant lesion was smaller than $3 \mathrm{~cm}$ in diameter. In 14 patients in whom the FNA was nondiagnostic, two masses proved to be malignant.

Although it has been suggested that FNA is useful in the differential diagnosis of a cystic adrenal mass, we strongly object to such practice because cystic pheochromocytomas are prevalent. Diagnostic puncture of such a lesion (or of a rare cystic echinococcal parasitic cyst) can be harmful to the patient. The possibility of seeding a malignant adrenal neoplasm in the retroperitoneum is an additional reason that FNA should be discouraged.

\section{Genetic and Molecular Biology Studies}

Currently, the only accepted criteria to determine whether an adrenaloma is benign or malignant are metastasis (synchronous or metachronous) and local invasion into adjacent structures. The mapping and identification of genes responsible for hereditary syndromes (e.g. multiple endocrine neoplasia type 1, LiFraumeni) have increased our understanding of adrenocortical tumorigenesis. Oncogenes and tumor suppressor genes involved in adrenal carcinomas include mutations in the p53 tumor suppressor gene. Several antibodies have been tested to study alterations in the p53 tumor suppressor gene. Amongst those, the Ki67 index (\% immunopositive cells) when above 5\% can be a useful indicator in the differentiation of adenomas from carcinomas..$^{52}$ Adrenal carcinomas are monoclonal, whereas adrenal adenomas may be polyclonal in approximately $25-40 \%$ of cases. ${ }^{53}$ Although these findings do not have direct clinical application, it is hoped that future research will facilitate the diagnosis and predict the natural course of these tumors.

\section{MANAGEMENT OF ADRENALOMAS: SURGERY VERSUS FOLLOW-UP}

Several recent studies that we briefly discussed demonstrated that:

a) A relatively high percentage of adrenalomas, especially adrenal cortical adenomas, are subclinically functioning 

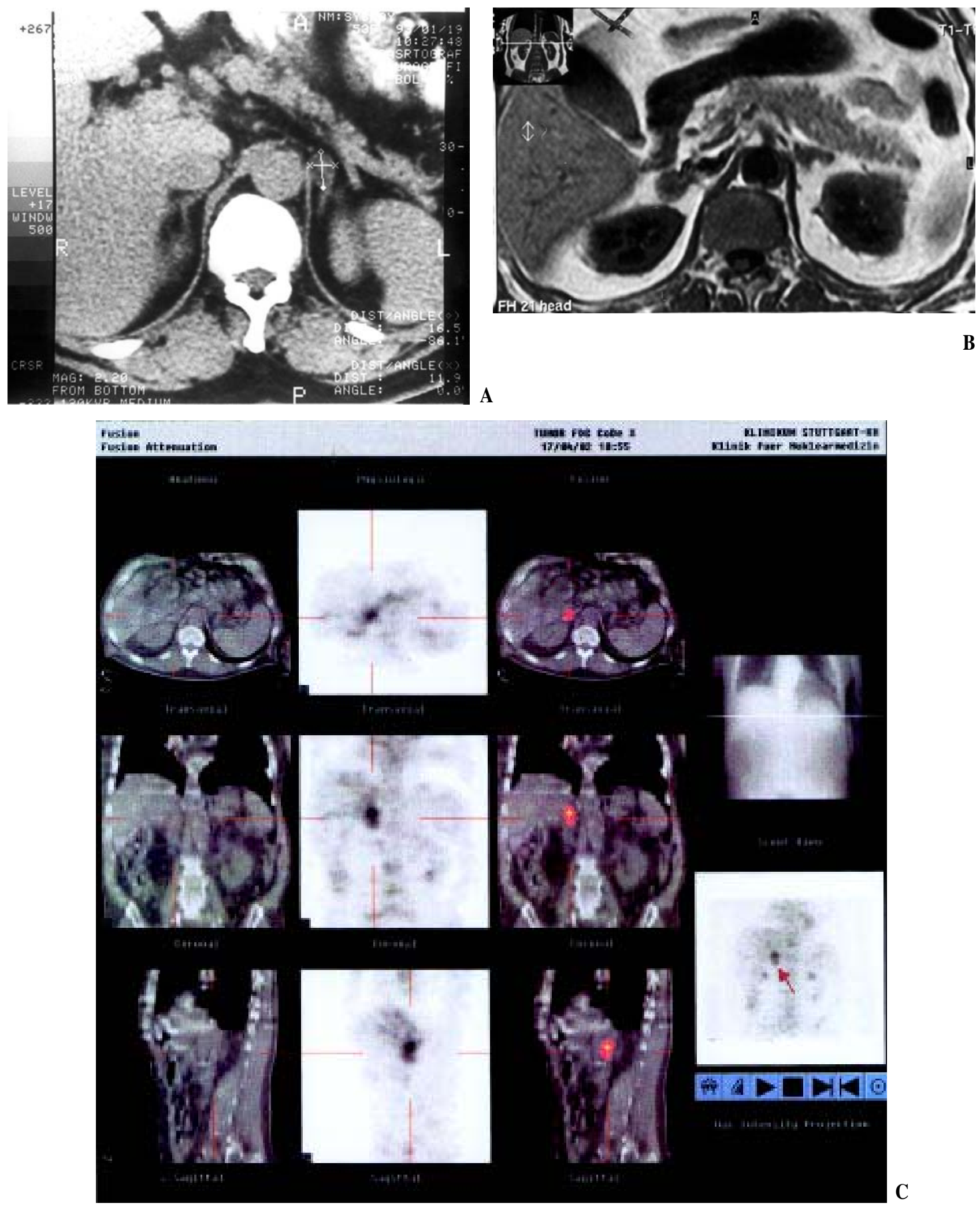

Figure 2. The classical imaging techniques for the adrenaloma: a) CT scan and b) MRI scan have recently been complemented by the addition of, c) The PET scan that occasionally can detect small metastatic adrenal tumors (usually for lung cancer) before their detection from MRI/ $\mathrm{CT}$ as it was the case for this 68 year-old man 
b) A relatively high percentage of patients with adrenaloma display pathological features such as: impaired glucose tolerance, insulin resistance, increased blood pressure, high triglyceride levels, low HDL, central fat deposition and reduced trabecular bone mineral density

c) When adrenalectomy was done in patients who either had proven subclinical hypercortisolism or even truly nonfunctioning tumors, the associated abnormalities and symptoms (such as hypertension, obesity, altered glucose tolerance, etc) were normalized or significantly improved.

In the era of laparoscopic adrenalectomy that carries a minimal mortality and morbidity, it appears logical to advocate surgery in patients with adrenaloma when

1. There is laboratory evidence for a subclinically functioning tumor

2. There are associated pathological features such as hypertension, impaired glucose tolerance (or diabetes), pathological triglyceride profile, central fat deposition, reduced bone mineral density

3. There is clinical and radiological evidence for primary or solitary metastatic adrenal carcinoma.

The age and the anxiety of the patient should also play a role in the decision to operate or not.

A conservative management is recommended for those patients with adrenaloma in whom: a) There is no clinical or laboratory evidence for subclinical function of the tumor; b) there are no associated symptoms potentially related to the adrenaloma; c) there is no suspicion of adrenal carcinoma. In these patients a yearly check-up should be continued for 5-10 years with the main emphasis on the possibility that the silent, non-functioning tumor may develop hyperfunction.

Limited, complete follow-up studies (with repeated radiologic and hormonal evaluation) have been performed on patients with adrenalomas. Barzon and associates $^{54}$ followed 75 patients with adrenaloma ${ }^{6}$, observed for a median of 4 years, and found 9 adrenalomas to have enlarged. Overt Cushing's syndrome developed in two patients, subclinical Cushing's syndrome in three and clinical pheochromocytoma in one. No patient had a malignancy. The esti- mated cumulative risks for mass enlargement and hyperfunction were $18 \%$ and $9.5 \%$ respectively after 5 years, and $22.8 \%$ and $9.5 \%$ after 10 years. In a recent study $^{55}, 53$ patients with adrenalomas were followed for 6-78 months (medium 24 months). During the follow-up, 22 lesions (41.5\%) increased in size and 6 lesions $(11.3 \%)$ decreased in size or disappeared. No adrenaloma grew or developed hypersecretion. Thus, during follow-up of the truly nonfunctioning adrenalomas, yearly hormonal evaluation should be emphasized rather than repeated imaging studies.

\section{WHAT IS THE BEST SURGICAL APPROACH IN THE MANAGEMENT OF THE ADRENALOMAS?}

Traditionally, surgical approaches to the adrenals have been anterior transperitoneal, posterior extraperitoneal and thoracoabdominal (for large tumors). ${ }^{56}$ The application of laparoscopic techniques in the surgery of the adrenal glands has essentially replaced all traditional open approaches in the same manner as laparoscopic cholecystectomy has replaced the traditional open cholecystectomy. Because there are so many benefits associated with the laparoscopic approach, open andrenalectomy should be reserved for very large adrenal carcinomas invading the surrounding tissue. We have compared the anterior, posterior and laparoscopic approach in 165 patients who underwent adrenalectomy between 1984 and $1994 .{ }^{57} \mathrm{Al}-$ though in this study we included our early cases and learning experience, the advantages of the laparoscopic approach were clearly shown in terms of morbidity (12.2\% in the anterior approach, $8.1 \%$ in the posterior approach and $0 \%$ in the laparoscopic approach), mean operating time, mean length of postoperative hospitalization (8.1 days versus 4.5 days versus 2.7 days) and minimal postoperative pain. The lack of long incisions and their immediate and long-term complications (e.g., wound infection, hernia, esthetic dissatisfaction) and the opportunity for an early return to full activity make the laparoscopic approach the procedure of choice for nearly all adrenalomas, including the laparoscopically removable primary or secondary carcinomas $^{58,31}$ (Figure 3). Although the posterior open adrenalectomy has more advantages than the anterior open andrenalectomy, the advantages of anterior laparoscopic adrenalectomy outweigh the advantages of the posterior laparoscopic approach. ${ }^{59,60}$ The anterior (or lateral) laparoscopic adrenalectomy enables 


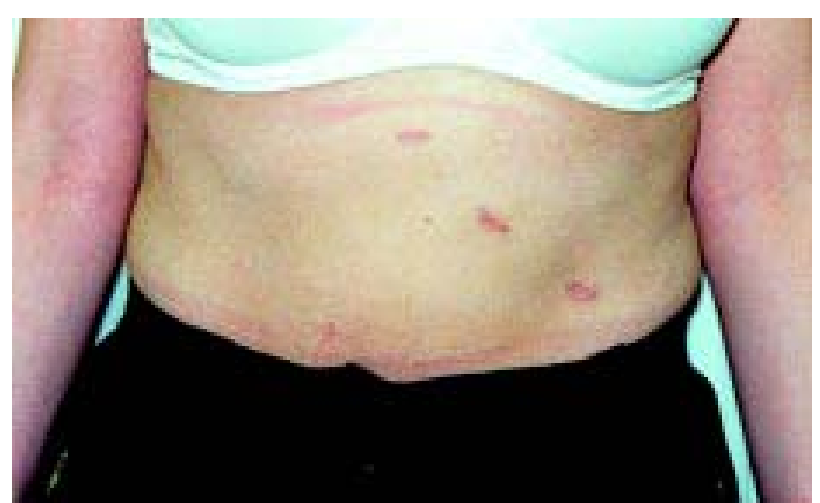

Figure 3. The laparoscopic adrenalectomy is ideal for the patient since it requires minimal skin incision as seen in a 52 y.o. female a week after surgery, for a $4.5 \mathrm{~cm}$ subclinical functioning adenoma.

the removal of large tumors, the performance of additional procedures (e.g. cholecystectomy) and the performance of bilateral laparoscopic adrenalectomies when indicated. ${ }^{61,62}$ We have simplified the anterior laparoscopic technique ${ }^{63}$ which has become easier and more "friendly" to the surgeon compared to the originally described techniques ${ }^{58}$. Thus, more and more surgeons will switch to the laparoscopic approach for the management of adrenal tumors.

\section{REFERENCES}

1. Linos D, 1989 Adrenaloma: a better term than incidentaloma. Surgery 105: 456.

2. Copeland PM, 1984 The incidentally discovered adrenal mass. Ann Surg 199: 116-112.

3. Siren J, Haapiainen RK, Huikuri KT, et al, 1993 Incidentalomas of the adrenal gland: 36 operated patients and review of literature. World J Surg 17: 634-639.

4. Young AE and Smellie WD 2001 The Adrenal Glands in Endocrine Surgery J.R. Farndon (ed.) WB Saunders London; pp, 123-124.

5. Ross NS, Aron DC, 1990 Hormonal evaluation of the patient with an incidentally discovered adrenal mass. $\mathrm{N}$ Engl J Med 323: 1401-1405.

6. Barzon L, Boscaro M, 2000 Diagnosis and management of adrenal incidentalomas. J Urol 163: 398-407.

7. Mantero F, Terzolo M, Arnaldi G, et al, 2000 A Survey on Adrenal Incidentaloma in Italy. J Clin Endocrinol Metab 85: 637-644.

8. Terzolo M, Bossoni S, Ali A, et al, 2000 Growth Hormone (GH) Responses to GH-Releasing Hormone Alone or Combined with Arginine in Patients with Adrenal Incidentaloma: Evidence for Enhanced Somatostatinergic Tone. J Clin Endocrinol Metab 85: 1310-1315.

9. Terzolo M, Pia A, Ali A, et al, 2002 Adrenal Incidentaloma: A New Cause of the Metabolic Syndrome. J Clin
Endocrinol Metab 87: 998-1003.

10. Rossi R, Tauchmanova L, Luciano A, et al, 2000 Subclinical Cushing's Syndrome in Patients with Adrenal Incidentaloma: Clinical and Biochemical Features. J Clin Endocrinol Metab 85: 1440-1448.

11. Midorikawa S, Sanada H, Hashimoto S, Suzuki T, Watanabe T, 2001 The improvement of insulin resistance in patients with adrenal incidentaloma by surgical resection. Clin Endocrinol 54: 797-804.

12. Fernadez-Real JM, Engel WR, Simon R, et al, 1998 Study of glucose tolerance in consecutive patients harbouring incidental adrenal tumours. Study Group of Incidental Adrenal Adenoma. Clin Endocrinol 49: 53-61.

13. Garrapa GGM, Pantanetti P, Arnaldi G, Mantero F, Faloia E, 2001 Body Composition and Metabolic Features in Women with Adrenal Incidentaloma or Cushing's Syndrome. J Clin Endocrinol Metab 86: 5301-5306.

14. Chiodini I, Torlontano M, Carnevale V, et al, 2001 Bone Loss Rate in Adrenal Incidentalomas: A Longtitudinal Study. J Clin Endocrinol Metab 86: 5337-5341.

15. Young WF, 2000 Management approaches to adrenal incidentalomas. A view from Rochester, Minnesota. Endocrinol Metab Clin North Am 29: 159-185.

16. Abecassis M, McLoughlin MJ, Langer B, et al, 1985 Serendipitous adrenal masses: Prevalence, significance and management. Am J Surg 149: 783-788.

17. Herrera MF, Grant CS, van Heerden JA, et al, 1991 Incidentally discovered adrenal tumors: an institutional perspective. Surgery 110: 1014-1021.

18. Caplan RH, Srutt PJ, Wickus G, 1994 Subclinical hormone secretion by incidentally discovered adrenal masses. Arch Surg 129: 291-296.

19. Prinz RA, Brooks MH, Churchill R, et al, 1982 Incidental asymptomatic adrenal masses detected by computed tomographic scanning. Is operation required? JAMA 248 : 701-704.

20. Glazer HS, Weyman PJ, Sagel SS, et al, 1982 Nonfunctioning adrenal masses: incidental discovery on computed tomography. AJR Am J Roentgenol 139: 81-85.

21. Belldegrun A, Hussain S, Seltzer SE, et al, 1986 Incidentally discovered mass of the adrenal gland. Surg Gynecol Obstet 163: 203-208.

22. Mantero F, Masini AM, Opocher G, et al, 1997 Adrenal incidentaloma: an overview of hormonal data from the National Italian Study Group. Horm Res 47: 284-289.

23. Linos DA, Stylopoulos N, Raptis SA, 1996 Adrenaloma: a call for more aggressive management. World J Surg 20: 788-792.

24. Bitter DA, Ross DS, 1989 Incidentally discovered adrenal masses. Am J Surg 158: 159-161.

25. Caplan RH, Kisken WA, Huiras CM, 1991 Incidentally discovered adrenal masses. Minn Med 74: 23-26.

26. Cajraj H, Young AE, 1993 Adrenal incidentaloma. Br J Surg 80: 422-426.

27. Geelhoed GW, Druy EM, 1992 Management of the adrenal "incidentaloma". Surgery 92: 866.

28. Didolkar MS, Bescher RA, Elias EG, et al, 1984 Natural history of adrenal cortical carcinoma: A clinicopatholog- 
ic study of 42 patients. Cancer 47: 2153.

29. Sutton MG, Sheps SG, Lie JT, 1981 Prevalence of clinically unsuspected pheochromocytoma: Review of a 50year autopsy series. Mayo Clin Proc 56: 354-360.

32. Aso Y, Homma Y, 1992 A survey on incidental adrenal tumors in Japan. J Urol 147: 1478-1481.

33. Terzolo M, Ali A, Osella G, et al, 1997 Prevalence of adrenal carcinoma among incidentally discovered adrenal masses. A retrospective study from 1989 to 1994. Gruppo Piemontese Incidentalomi Surrenalici. Arch Surg 132: 914919.

34. Yamakita N, Saitoh M, Mercado-Asis LB, et al, 1990 Asymptomatic adrenal tumor; 386 cases in Japan including our 7 cases. Endocrinol Jpn 37: 671-684.

35. Fernadez-Real JM, Gonzalbez J, Ricart W, 2001 Metabolic Abnormalities in Patients with Adrenal Incidentaloma [Letters to the Editor]. J Clin Endocrinol Metab 86: 950-951.

36. Terzolo M, Osella G, Ali A, et al, 1998 Subclinical Cushing's syndrome in adrenal incidentaloma. Clin Endocrinol 48: 89-97.

37. Chidiac RM, Aron DC, 1997 Incidentalomas. A disease of modern technology. Endocrinol Metab Clin North Am 26: 233-253.

38. Beuschlein F, Borgemeister M, Schirra J, et al, 2000 Oral glucose tolerance testing but not intravenous glucose administration uncovers hyper-responsiveness of hypothalamo-pituitary-adrenal axis in patients with adrenal incidentalomas. Clin Endocrinol 52: 617-623.

39. Barzon L, Scaroni C, Sonino N, et al, 1998 Incidentally discovered adrenal tumors: endocrine and scintigraphic correlates. J Clin Endocrinol Metab 83: 55-62.

40. Dwamena BA, Kloos RT, Fendrick AM, et al, 1998 Diagnostic evaluation of the adrenal incidentaloma: decision and cost-effectiveness analysis. J Nucl Med 39: 707-712.

41. Ito Y, Obara T, Okamoto T et al, 1998 Efficacy of singlevoided urine metanephrine and normetahephrine assay for diagnosing pheochromocytoma. World J Surg 22: 684.

42. Linos DA, 2000 Management approaches to adrenal incidentalomas (adrenalomas). A view from Athens, Greece. Endocrinol Metab Clin North Am 29: 141-157.

43. Gordon RD, Ziesak MD, Tunny TJ, et al, 1993 Evidence that primary aldosteronism may not be uncommon: $12 \%$ incidence among antihypertensive drug trial volunteers. Clin Exp Pharmacol Physiol 20: 296-298.

44. Gordon R, Stowasser M, Rutherfort J, 2001 Primary Aldosteronism: are we diagnosing and operating on too few patients? World J Surg 25: 941-947.

45. Proye C, Jafari Manjili M, Combemale F, et al, 1998 Experience gained from operation of 103 adrenal incidentalomas. Langenbecks Arch Surg 338: 330-333.

46. Schteingart DE, 2000 Management approaches to adrenal incidentalomas. A View from Ann Arbor Michigan. Endocrinol Metab Clin North Am 29: 127-139.
47. Linos DA, Avlonitis VS, Iliadis K, 1998 Laparoscopic resection of solitary adrenal metastasis from lung carcinoma: a case report. JSLS 2: 291-293.

48. Linos DA, Stylopoulos N, 1997 How accurate is computed tomography in predicting the real size of adrenal tumors? A retrospective study. Arch Surg 132: 740-743.

49. Udelsman R, Fishman EK, 2000 Radiology of the adrenal. Endocrinol Metab Clin North Am 29: 27-42.

50. Yun M, Kim W, Alnafisi N, Lacorte L, Jang S, Alavi A, 200118 F-FDG PET in characterizing adrenal lesions detected on CT or MRI. J Nucl Med 42: 1795-1799.

51. Silverman SG, Mueller PR, Pinkey LP, et al, 1993 Predictive value of image-guided adrenal biopsy: analysis and results of 101 biopsies. Radiology 187: 715-718.

52. Wachenfeld C, Beuschlein F, Swermann O, et al, 2001 Discerning malignancy in adrenocortical tumors: are molecular markers useful? Eur J Endocrinology, 145: 335341.

53. Reincke M, Beuschlein F, Slawik M, Borm K, 2000 Molecular adrenocortical tumourgenesis. Eur J Clin Invest 30: 63-68.

54. Barzon L, Scaroni C, Sonino, et al, 1999 Risk factors and long-term follow-up of adrenal incidentalomas. J Clin Endocrinol Metab 84: 520-526.

55. Grossrubatscher E, Vignati F, Posso M, Lohi P, 2001 The natural history of incidentally discovered adrenocortical adenomas: a retrospective evaluation. J Endocrinol Invest 24: 846-855.

56. Linos DA 1989 Surgical approach to the adrenal gland. In: van Heerden JA (ed) Common Problems in Endocrine Surgery, Recommendations of the Experts, St. Louis, Year Book Medical; pp, 349-355.

57. Linos DA, Stylopoulos N, Boukis M, et al, 1997 Anterior, posterior or laparoscopic approach for the management of adrenal diseases? Am J Surg 173: 120-125.

58. Gagner M, Pomp A, Heniford BT, et al, 1997 Laparoscopic adrenalectomy: lessons learned from 100 consecutive procedures. Ann Surg 226: 238-246.

59. Thompson GB, Grant CS, van Heerden JA, et al, 1997 Laparoscopic versus open posterior adrenalectomy: a case-control study of 100 patients. Surgery 122: 1132-1136.

60. Ting Ac, Lo CY, Lo CM, 1998 Posterior or laparoscopic approach for adrenalectomy. Am J Surg 175: 488-490.

61. Lanzi R, Montorsi F, Losa M, et al, 1998 Laparoscopic bilateral adrenalectomy for persistent Cushing's disease after transsphenoidal surgery. Surgery 123: 144-150.

62. Miccoli P, Raffaelli M, Berti P, Materazzi G, Massi M, Bernini G, 2002 Adrenal surgery before and after the introduction of laparoscopic adrenalectomy. Br J Surg 89: 779-782.

63. Linos D 2002 Laparoscopic right adrenalectomy in Operative Techniques in General Surgery. JA vanHeerden, DF Farley (eds), W.B. Saunders (in press). 